\title{
ALLELIC VARIATION OF HMW GLUTENIN SUBUNITS OF ETHIOPIAN BREAD WHEAT CULTIVARS AND THEIR QUALITY
}

\author{
TADESSE DESSALEGN, C.S. VAN DEVENTER ${ }^{1}$, M.T. LABUSCHAGNE ${ }^{1}$ and H. MARTENS ${ }^{1}$ \\ Bahir Dar University, P. O. Box 2073, Bahir Dar, Ethiopia \\ ${ }^{1}$ Department of Plant Sciences, University of Free State, P. O. Box 339, Bloemfontein, South Africa \\ Corresponding author: tadesseyfb@yahoo.com
}

(Received 25 October, 2010; accepted 20 May, 2011)

\begin{abstract}
High molecular weight glutenins are often effective in identifying wheat (Triticum aestivum) genotypes with good baking quality. The high molecular weight glutenin subunit composition of Ethiopian cultivars and advanced lines was investigated to determine their influence on quality. Three alleles at Glu-A1, five at Glu-Bl and two at Glu$D 1$ and eleven different banding patterns were identified. Few cultivars had biotypes at Glu-Al and Glu-Dl loci. There were highly significant differences between genotypes and banding patterns for the SDS-sedimentation test, mixograph development time, alveograph strength and loaf volume; but not for protein content. The frequency of subunits $5+10$ among genotypes was $73 \%$. The accumulation of high scoring alleles in our germplasm was without deliberate selection pressure towards high Glu-1 scoring alleles during breeding. Introductions from CIMMYT are widely used and such materials might have gone through selection and accumulation of such alleles at CIMMYT. Most of the studied materials had the required subunits of high quality scores and better values of the quality traits than originally thought. Therefore, the concern about poor baking quality is unlikely to be due to $G l u-1$ allelic variations alone.
\end{abstract}

Key Words: Allelic variation, grain quality, HMW glutenins

\section{RÉSUMÉ}

Le poids moléculaire élevé des glutanines est souvent un moyen efficace pour identifier les génotypes du blé (Triticum aestivum) doté de bonnes qualités patissières. Une investigation était faite sur le poids moléculaire élevé des glutanines des sous unités des cultivars éthiopiens ainsi que sur des lignées avancées pour déterminer leur influence sur la qualité. Trois allèles à $G l u-A 1$, cinq à $G l u-B 1$ et deux à $G l u-D 1$ ainsi que onze différents modes de bandage étaient identifiés. Peu de cultivars avaient des biotypes à $G l u-A l$ et $G l u-D l$ loci. Une différence hautement significative était observée entre génotypes et modes de bandage pour le test de sédimentation SDS, le temps de développement de mixographe, la force de l'alvéographe et le volume du pain mais non au contenu en protéines. La fréquence des sous unités 5+10 parmi les génotypes était 73\%. L'accumulation des allèles à score plus élevé dans notre germoplasme avait eu lieu sans sélection délibérée de la pression des allèles à score plus élevé en Glu1 pendant le breeding. Des introductions de CIMMYT sont largement utilisées et de tels matériels devraient passer par la sélection et l'accumulation de telles allèles au CIMMYT. La plupart des matériels étudiés possédaient de sous unités requises avec de scores de haute qualité et meilleures valeurs de traits de qualité qu'on ne le pensait originellement. Par conséquent, le problème concernant la pauvre qualité patissière n'était pas seulement dû aux variations alléliques $\mathrm{Glu}-1$.

Mots Clés: Variations alléliques, grain de qualité, glutenines HMW 


\section{INTRODUCTION}

Wheat (Triticum aestivum L. and Triticum turgidum L. (Thell.) ssp. durum (Desf.) Husn.) are among the leading cereals in Ethiopia. The country is considered as a primary centre of diversity for tetraploid wheats (Vavilov, 1931) and contemporarily, it has the greatest diversity (Alamerew et al., 2004). The country is the second largest wheat producer in Eastern, Central and Southern Africa (Tanner and Mwangi, 1991; Payne et al., 2001). Bread wheat is expanding in area of production at the expense of traditional durum and emmer wheat crops because of its broader adaptability and yield advantage (Hailu , 1991; Payne et al., 2001). However, the yield per unit area is low due to influence of various technical and socioeconomic constraints.

Wheat improvement of northwestern Ethiopia is mainly targeted to develop high yielding, widely adapted and disease resistant varieties; with inadequate emphasis on grain quality. It is expected that the deterioration of milling and baking quality might occur during the development of varieties for high grain yield (Bingham and Lupton, 1987). The need for improved quality of raw material for the wheat industry is increasing and some milling enterprises and traders import grain and flour. Improvement for both reasonable yield and quality must be given higher emphasis in the breeding programmes to satisfy the growing needs.

One of the major prerequisite of quality is the presence of intrinsic protein quality. Proteins are useful markers of quality (Payne, 1987). Studies indicate that $20-60 \%$ of the variability between varieties in bread making quality can be accounted for by variation in grain storage proteins (Payne, 1987; Lukow et al., 1989; Kolster et al., 1991; Worland and Snape, 2001). In sodium dodecyl sulfate-poly acrylamide gel electrophoresis (SDS-PAGE), two groups of reduced subunits of glutenin proteins bands are separated: the high molecular weight (HMW) and low molecular weight (LMW) subunits (Payne et al., 1980; Jackson et al., 1983). The HMW glutenin subunits (GS) of wheat protein are quantitatively minor, but functionally an important group of gluten proteins in the process of bread making.
They are encoded at the Glu-1 loci on the long arm of the group 1 chromosome $1 \mathrm{~A}, 1 \mathrm{~B}$, and 1D at $G l u-A 1, G l u-B 1$ and $G l u-D 1$ loci, respectively (Payne, 1987).

The relationships between HMW-GS and bread making quality were studied as the presence and absence of subunits (Payne et al., 1987) or as the quantity of one subunit related to quality (Ng and Bushuk, 1988; Weegels et al., 1996); and the additivity or combined role of HMW- and LMW-GS in improving bread making quality (Payne et al., 1987; Gupta et al., 1989). Other grain components, such as lipids and carbohydrates also affect bread making quality, possibly by interacting with the gluten proteins. Correlations and genetic studies of HMW-GS (Pogna et al., 1986; Payne et al., 1987) established subunits with both positive $(5+10)$ and negative $(2+12)$ effects on bread making quality. Other allelic variant pairs showed similar results (Payne, 1987). In general, a null at Glu-Al locus, subunit $6+8$ encoded at Glu-Bl and $2+12$ at Glu-Dl are negatively related with the quality parameters (Weegels et al., 1996).

A scoring system for HMW-GS has been developed (Pogna and Mellini, 1986; Payne et al., 1987) as the sum of the contributions of each of the three HMW-GS loci. Many breeding programmes have characterised the HMW-GS composition of breeding and released lines/ cultivars (Payne et al., 1987; Morguno, 1990; Lukow et al., 1989; Igregas et al., 1999; Nakamura, 2001) in relation with end-use quality and used as a screening test to ensure that good bread making alleles $(1,2 *, 7+9,7+8,5+10)$ are incorporated in new cultivars (Lukow, 1991). However, the HMW-GS score has more influence in some sets of wheats than in others (MacRitchie et al., 1990; Bedõ et al., 1995). Nevertheless, reference to HMW-GS composition has proved valuable in the segregation of lines in the process of breeding for specific quality targets (Weegels, et al., 1996; Cornish et al., 1999) and as indicators of quality when only small amounts of the material are available and fast quality prediction is necessary (Weegels et al., 1996).

Selection for these quality alleles will help to reduce the cost of extensive field evaluations of large scale materials, which can sometimes end up with inferior quality. Few lines/varieties 
selected for quality alleles will be included in the regional variety trials, checked for their improved quality and authenticity.

This study investigated the popular commercial and advanced breeding lines from Ethiopia for HMW protein composition and HMW scores for quality and relationships with some physical measures of quality.

\section{MATERIALS AND METHODS}

Thirty wheat genotypes were sampled from two categories: from the widely grown commercial (registered) cultivars and from fixed advanced lines for possible release (Table 1). The advanced lines were in a series of field trials, regional and national, for the last 7-8 years and were selected for agronomic superiority. The experiment was located at Bainsvlei, South Africa, with an altitude of $1372 \mathrm{~m}$; sandy loam soil and with a mean annual rainfall of $510 \mathrm{~mm}$. The materials were grown in the same environment to avoid environmental variation and to see real varietal differences. South African cultivars were included for comparison. A randomised complete block design in three replications was used. All agronomic practices were standard for wheat production in the area.

Polyacrylimide gel electrophoresis in the presence of Sodium Dodecyl Sulfate (SDS-PAGE) of glutenins of the seeds, was carried out using

TABLE 1. L List of cultivars/lines used

\begin{tabular}{llll}
\hline Line no. & Cultivar (line) & Line no. & Cultivar (line) \\
\hline 1 & HAR 2457 & 16 & HAR 1709 \\
2 & HAR 1918 & 17 & HAR 1685 \\
3 & HAR 2258 & 18 & HAR 604 \\
4 & HAR 2348 & 19 & HAR 1522 \\
5 & HAR 2566 & 20 & HAR 1775 \\
6 & HAR 2807 & 21 & HAR 1868 \\
7 & HAR 2029 & 22 & HAR 1847 \\
8 & HAR 2408 & 23 & HAR 1920 \\
9 & HAR 1896 & 24 & HAR 2536 \\
10 & HAR 2096 & 25 & HAR 2501 \\
11 & HAR 2530 & 26 & HAR 2504 \\
12 & HAR 2562 & 27 & HAR 2505 \\
13 & HAR 1899 & 28 & HAR 2192 \\
14 & K6295-4A & 29 & Kariega \\
15 & ET13A & 30 & SST-825 \\
\hline
\end{tabular}

the procedure of Singh et al. (1991). Six seeds were sampled for each genotype, and each seed was crushed into fine powder mortar and pestle. The gliadins were extracted and removed in $70 \%$ ethanol and 50\% $n$-propanol to avoid contamination of glutenins. Glutenins were extracted and reduced from the residue in extraction buffer containing dithiothretol (DTT) and the protein was alkylated using 4vinylpyridin. Finally, SDS was added and incubated. This complexed SDS with the reduced and alkylated glutenin polypeptides. A gel of $10 \%$ acrylamide concentration was used for separation and Coomassie brilliant blue R-250 (0.05 $g$ ) for staining of proteins.

The HMW glutenin subunits were identified using the numbering system of Payne and Lawrence (1983). The quality scores were calculated using the methods of Payne et al. (1987) and Pogna and Mellini (1986) (Table 2). The materials were studied for variability in the expression of protein content (FPC, percentage, AACC 39-11), mixograph development time (MDT, min, AACC 54), SDS Sedimentation test (SDSS, $m l$, AACC 56-70), alveograph strength (W, $\mathrm{cm}, \mathrm{AACC} 54-30 \mathrm{~A}^{2}$ ) and loaf volume ( $\mathrm{LFV}, \mathrm{cm}^{3}$, AACC 10-09). Analysis of variance was carried out in general linear model (GLM) of NCSS software (2001) using varieties and banding patterns as factors. Rank correlation analysis was calculated between quality parameters.

\section{RESULTS AND DISCUSSION}

Three alleles at Glu-Al locus (a, b and c) of chromosome 1A, five at Glu-Bl (a, b, c, i and f) of chromosome 1B; and two at Glu-Dl (a and d) of chromosome 1D were identified (Table 3). Rare alleles were Glu-Alc, Glu-Blf and Glu-B1a. GluAla (2*), Glu-Blc (7+9) and Glu-Dla (5+10) appeared with a frequency of 74,55 and $78 \%$, respectively; compared with other alleles at each locus. The electrophoresis patterns of selected cultivars along with the standards are presented in Figure 1.

The joint occurrence of different alleles from the three loci is important in the accumulation of scores and also in determining quality (Payne et al., 1987). Twenty-one cultivars had subunits $5+10$, and six cultivars had $2+12$ at the Glu-Dl 
TABLE 2. Frequency of each allele (subunit) at different loci (Glu-A1, Glu-B1, Glu-D1)

\begin{tabular}{|c|c|c|c|c|c|c|c|c|}
\hline \multicolumn{3}{|c|}{ Glu-A1 } & \multicolumn{3}{|c|}{ Glu-B1 } & \multicolumn{3}{|c|}{ Glu-D1 } \\
\hline Subunit (Allele) & No. of lines & $\%$ & Subunit (Allele) & No. of lines & $\%$ & (Allele) Subunit & No. of lines & $\%$ \\
\hline 1 (a) & 6 & 22 & $7 \quad$ (a) & 2 & 7 & $5+10(a)$ & 21 & 78 \\
\hline $2^{*}(b)$ & 20 & 74 & $7+8$ (b) & 5 & 19 & $2+12$ (d) & 6 & 22 \\
\hline \multirow[t]{3}{*}{$N(c)$} & 1 & 4 & $7+9 \quad(c)$ & 15 & 55 & & & \\
\hline & & & $17+18$ (i) & 4 & 15 & & & \\
\hline & & & $13+16(f)$ & 1 & 4 & & & \\
\hline
\end{tabular}

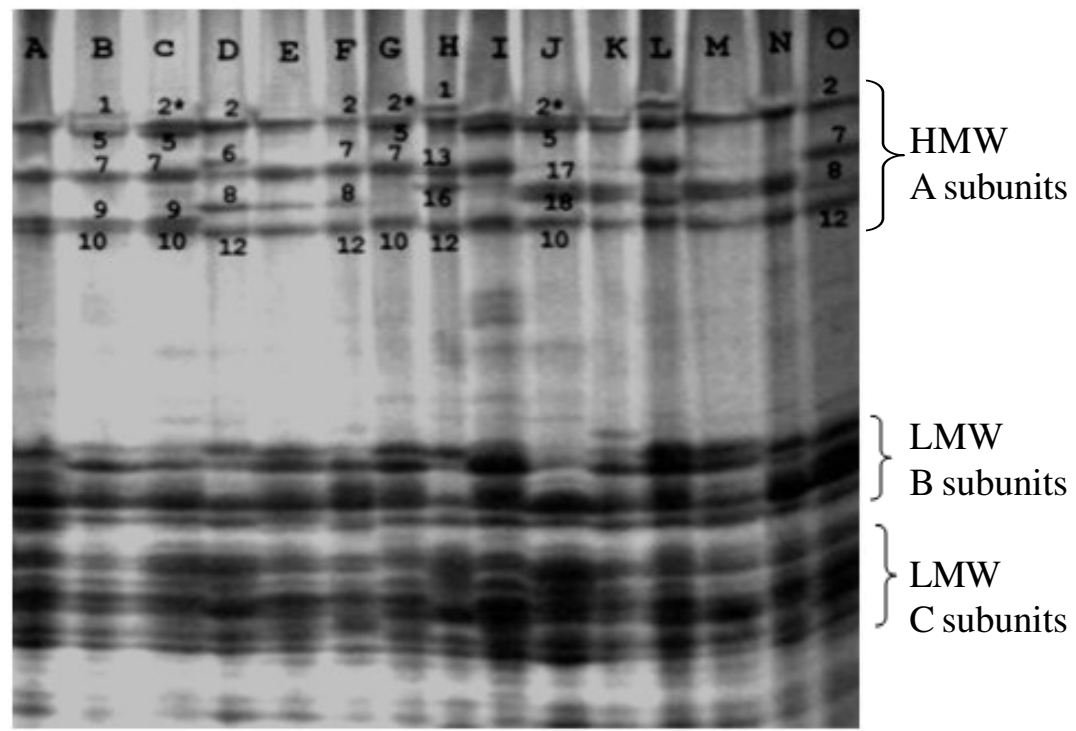

Figure 1. SDS-PAGE patterns of HMW of some lines and cultivars.

$\mathrm{A}=$ HAR1709; $\mathrm{B}=$ HAR1522; $\mathrm{C}=$ HAR1775; $\mathrm{D}=$ HAR2348; $\mathrm{E}=\mathrm{ET13A} ; \mathrm{F} \& \mathrm{O}=$ Chinese Spring; $\mathrm{G}=$ HAR1868; H = HAR2807; I = HAR1685; J = HAR2562; K = HAR604; L = SST-85; M = Kariega

TABLE 3. Joint occurring subunits of Glu-B1 and Glu-D1 subunits

\begin{tabular}{lccc}
\hline Glu-B1 & Glu-D1 & No. of lines & $(\%)$ \\
\hline 7 & $5+10$ & 2 & 7 \\
$7+8$ & $5+10$ & 1 & 4 \\
$7+9$ & $5+10$ & 15 & 55 \\
$17+18$ & $5+10$ & 3 & 11 \\
$13+16$ & $2+12$ & 1 & 4 \\
$7+8$ & $2+12$ & 4 & 15 \\
$17+18$ & $2+12$ & 1 & 4 \\
\hline
\end{tabular}

locus (Table 2), while three varieties showed biotypes. Generally, the presence of subunit $5+10$ is considered vital for indication of quality (Payne et al., 1987; Kasarda, 1999) and a maximum score is allocated for its presence. Subunit 5+10 mostly appeared with $7+9(55 \%)$ and $17+18(11 \%)$ alleles of $G l u-\mathrm{B} 1$, which resulted in the accumulation of high scores for most of the varieties. The widely accepted Glu-Dld $(2+12)$ subunits, caused deleterious effects on quality and appeared together with subunits $G l u-B 1 b(7+8)$ 
in three varieties out of six. Twenty six (96\%) of the varieties had five subunits/alleles at the three $G l u-l$ loci and no variety had six subunits as one of the allele at $G l u$-A 1 was always silent. Some varieties have been reported to have six subunits (Payne and Lawrence, 1983).

Eleven different subunit combinations at the three Glu-1 loci were identified among the 30 varieties studied; one pattern as a biotype (Table 4). Three varieties were excluded showing mixed banding patterns due to presence of biotypes. They showed variation at Glu-Al and Glu-Bl loci The most frequently appearing pattern was $2 *, 7+9,5+10(37 \%$, alleles b,c,a), found in 11 varieties; followed by $0 / 2 *, 7+8,2+12(13 \%$, alleles $\mathrm{c} / \mathrm{b}, \mathrm{b}, \mathrm{d})$, observed in three varieties. Among the 10 allelic combinations (patterns) at the three loci identified in the studied materials, five of them were represented by single line/cultivar each.

HMW subunits and patterns with high quality scores were observed in the majority of the cultivars and advanced lines (Table 4). The scores based on SDSS test ranged from 7 to 10 . Four of the cultivars had the maximum possible score of 10, i.e., two commercial, one advanced line and one South African included for comparison. Fourteen of the varieties had a score of 9. Generally, 26 out of 27 genotypes (96\%) had a quality score value ranging from 8 to 10 , indicating most accumulated higher quality scoring subunits.
The three varieties showing biotypes were uniform at the Glu-Dl locus, had 5+10 subunits (Glu-Dld); while one variety was heterogeneous at Glu-Al locus. As selection for the 5+10 subunits of $G l u-D 1$, for better quality, is the most widely used (MacRitchie et al., 1990; Lukow, 1991; Cornish et al., 1999), the sampled materials were dominated by the same allele $(73 \%)$. The accumulation of high scoring alleles in our germplasm was during selection for yield, wide adaptation and disease resistance. No selection pressure towards high Glu-1 scoring alleles was made in the breeding efforts because the wheat breeding programme priority objective was selection for high yield and disease resistance without considering for grain quality. Introductions from CIMMYT are widely used and such materials might have gone through selection and accumulation of high scoring Glu1 alleles at CIMMYT.

The score values using the method of Pogna and Mellini (1986) ranged from 9 to $17 ; 23$ genotypes. These scored greater than 13 showing higher values, which can be associated with quality (Table 4). The low scores were obtained by varieties having null alleles at $G l u$ A 1 , and single subunit allele at $G l u-B l$ combined with $2+12$ of Glu-Dl allele.

There was significant variability between genotypes in the quality traits studied except protein content (Tables 4 and 5). The non-

TABLE 4. Mean of quality traits and Glu-1 scores of the banding patterns at the three loci

\begin{tabular}{|c|c|c|c|c|c|c|c|c|}
\hline $\begin{array}{l}\text { Subunit } \\
\text { combination }\end{array}$ & Alleles & $\begin{array}{l}\text { MDT } \\
\text { (min) }\end{array}$ & $\begin{array}{c}\text { W } \\
\left(\mathrm{cm}^{2}\right)\end{array}$ & $\begin{array}{r}\text { SDSS } \\
(\mathrm{ml})\end{array}$ & $\begin{array}{l}\text { LFV } \\
\left(\mathrm{cm}^{3}\right)\end{array}$ & $\begin{array}{l}\text { SDSS } \\
\text { score }^{\mathrm{a}}\end{array}$ & $\begin{array}{c}\text { W } \\
\text { score }^{b}\end{array}$ & Line No. \\
\hline $1,7+8,5+10$ & $a, b, a$ & 2.9 & 56.4 & 88.3 & 994.3 & 10 & 13 & 30 \\
\hline $2^{*}, 17+18,5+10$ & $b, i, a$, & 2.8 & 44.5 & 79.7 & 858.7 & 10 & 17 & $12,13,18$ \\
\hline $2^{*}, 7+9,5+10$ & $b, c, a$ & 2.0 & 33.8 & 66.0 & 827.9 & 9 & 16 & $\begin{array}{l}2,5,7,8,9,10,16 \\
20,23,24,25\end{array}$ \\
\hline $1,7+9,5+10$ & $\mathrm{a}, \mathrm{c}, \mathrm{a}$ & 2.0 & 31.8 & 68.8 & 815.9 & 9 & 14 & $1,11,19$ \\
\hline $2^{*}, 7,5+10$ & $\mathrm{~b}, \mathrm{a}, \mathrm{a}$ & 1.9 & 27.6 & 77.5 & 931.5 & 8 & 13 & 17,21 \\
\hline$N, 7+9,5+10$ & $\mathrm{c}, \mathrm{C}, \mathrm{a}$ & 1.7 & 22.2 & 54.0 & 733.7 & 7 & 13 & 3 \\
\hline $1,7+8,2+12$ & $a, b, d$ & 2.6 & 39.1 & 81.0 & 887.7 & 8 & 9 & 28 \\
\hline $1,13+16,2+12$ & $a, f, d$ & 1.6 & 27.6 & 64.7 & 846.7 & 8 & 11 & 6 \\
\hline $0 / 2^{*}, 7+8,2+12$ & $c / b, b, d$ & 1.5 & 25.1 & 66.7 & 871.7 & 8 & 11 & $4,14,15$ \\
\hline $0 / 2^{*}, 17+18,2+12$ & $\mathrm{c} / \mathrm{b}, \mathrm{i}, \mathrm{d}$ & 2.6 & 43.1 & 91.7 & 1007.3 & 8 & 13 & 29 \\
\hline $1,7,5+10$ & $\mathrm{a}, \mathrm{a}, \mathrm{a}^{\dagger}$ & & & & & & & \\
\hline
\end{tabular}

t= biotype; ${ }^{a}=$ Payne et al., 1987; ${ }^{b}=$ Pogna et al., 1986 
TABLE 5. Mean squares of varieties and HMW banding patterns

\begin{tabular}{|c|c|c|c|c|}
\hline \multirow[t]{2}{*}{ Source } & \multicolumn{2}{|c|}{ Varieties } & \multicolumn{2}{|c|}{ HMW banding patterns } \\
\hline & Mean squares & F-value & Mean squares & F-value \\
\hline FPC (\%) & 1.5 & $1.52^{\mathrm{NS}}$ & 1.4 & $1.32^{\mathrm{NS}}$ \\
\hline MDT (min) & 1.0 & $20.9^{\star * *}$ & 1.5 & $6.5^{\star \star \star}$ \\
\hline SDSS (ml) & 374 & $47.5^{\star \star \star}$ & 603.7 & $9.09^{* * *}$ \\
\hline $\mathrm{W}\left(\mathrm{cm}^{2}\right)$ & 344.9 & $27.3^{* * *}$ & 486.7 & $6.56^{\star * *}$ \\
\hline $\operatorname{LFV}\left(\mathrm{cm}^{3}\right)$ & 16318.4 & $6.6^{\star \star \star}$ & 27905.4 & $6.45^{\star \star *}$ \\
\hline
\end{tabular}

*** indicates significant at $\mathrm{P}<0.001$; ${ }^{\mathrm{NS}}$, non-significant

significant differences in their protein contents will help to minimise the influence of protein on other parameters of quality.

The genotype mean values of MDT ranged from 1.1-3.2 min, alveograph strength (W) from 15.8 to $60.7 \mathrm{~cm}^{2}$, and SDSS from 52.7 to 91.7 $\mathrm{ml}$ and LFV from 731.3 to $1007.3 \mathrm{~cm}^{3}$. Three genotypes having the highest possible quality scores, i.e., cultivar No. 12, 13 and 18 varied in MDT, W and SDSS performances. Cultivar 12 was significantly different from the two others in SDSS, MDT and W, but not protein. Similar variation was also observed in the rest of the genotypes having similar banding patterns. Thus, genotypes with similar HMW patterns and high score alleles might not assure similarly higher values of quality parameters as other factors and their interactions are also involved in determining quality (Payne et al., 1987; Gupta et al., 1989). It was also demonstrated that contribution of HMW allelic combination alone in grain quality could range from 20 - 60\% (Payne et al., 1987; Lukow et al., 1989).

The mean FPC of the subunit patterns ranged from 12.1 to $13.5 \%$, MDT from 1.5 to $2.9 \mathrm{~min}$, SDSS from 54.0 to $91.7 \mathrm{ml}$ and loaf volume from 733.7 to $1007.3 \mathrm{~cm}^{3}$. The banding patterns significantly affected the traits studied except protein content (Table 5), showing that selecting for better alleles and their combinations is valuable. The first and third highest values of SDSS were achieved by patterns $0 / 2 *, 17+18,2+12$ and $1,7+8,2+12$, respectively. The $2^{\text {nd }}$ and $4^{\text {th }}$ highest value were, respectively, by $1,7+8,5+10$ and $2 *, 17+18,5+10$. To the contrary, cultivar Kariega with 0/ $2 *, 17+18,2+12$ with lower quality score had high SDSS and LFV values and reasonably high values of MDT and W. It was reported that the HMW glutenin score has more influence in some sets of wheats than in others (MacRitchie et al., 1990) and also lines with poor banding combinations $(2+12)$ produce a relatively high volume (Bedo et al., 1995). This is likely to be due to the complex interaction of factors that define wheat quality.

The two highest MDT and $\mathrm{W}$ values were scored by the patterns allelic combinations having the maximum score of 10 and $5+10$ bands at Glu-D1 locus. This was followed by two cultivars holding $2+12$ with SDSS score of 8 (Figs. 2 and 3). The lowest values in MDT, SDSS and $\mathrm{W}$ were achieved by patterns having $2+12$ bands. Pattern N,7+9,5+10, with the lowest SDSS score of 7, was a poor performer in all traits, indicating the null allele of Glu-A1 should be avoided in selection (Payne et al., 1987, Weegles et al., 1996). The three patterns $1,7+8,5+10 ; 0 / 2 *, 17+18,2+12$ and $2 *, 7,5+10$ had the highest LFV.

Loaf volume was significantly and positively correlated to SDSS $(0.74 * * *)$, MDT $(0.32 * *)$ and alveograph $\mathrm{W}\left(0.33^{* *}\right)$. The highest valuable allelic combinations in these materials were $1,7+8,5+10$ and $2 *, 17+18,5+10$ in MDT, $2^{*}, 17+18,2+12$ and $1,7+8,5+10$ in SDSS; $1,7+8,5+10$ and $2 *, 17+18,5+10$ in alveograph $\mathrm{W}$, and $2 *, 17+18,2+12$; and $1,7+8,5+10$ in LFV.

In the cultivars/lines studied, varieties having $5+10$ subunits had higher frequencies and generally gave better quality results. Genotypes having similar patterns had variable expressions in the studied traits. There were also genotypes with subunits $2+12$ in their patterns which gave improved results like cultivars Kariega and HAR 2192. Avoiding the null allele at Glu-Al is 


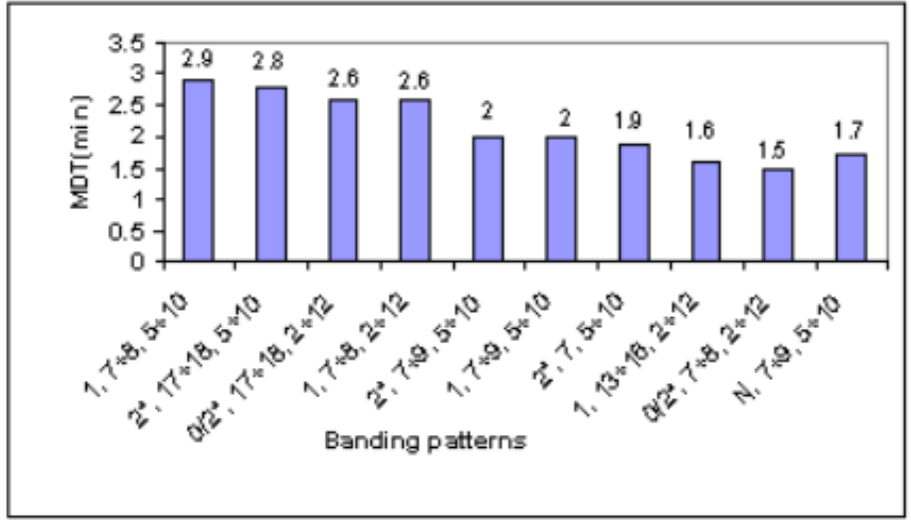

Figure 2. Mixograph development time (MDT) of 10 banding patterns.

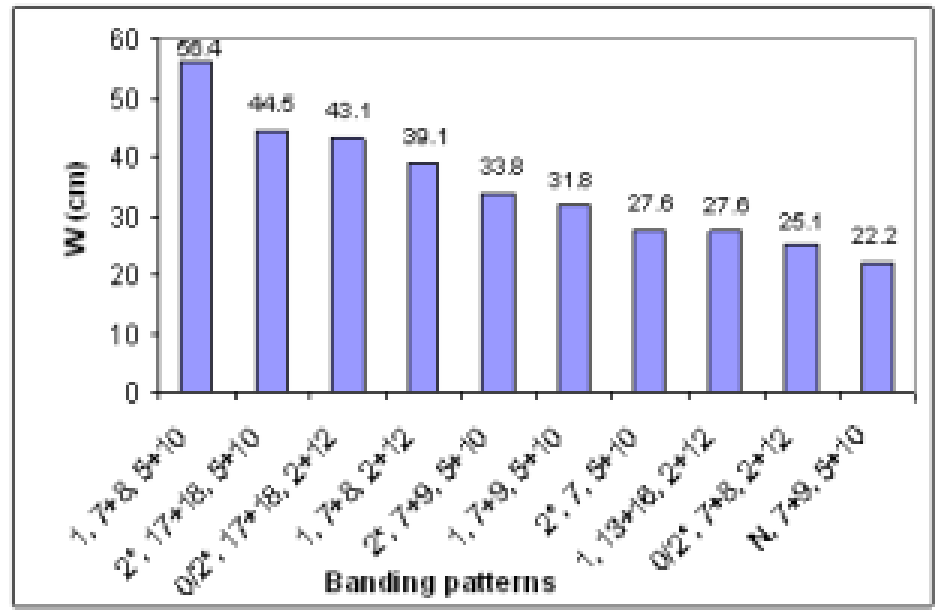

Figure 3. Gluten strength (W) values of 10 banding patterns.

important. For better results, breeding and selection using HMW glutenin subunits and Glu1 scores (Wrigley, 2002) combined with one or more direct physical (MDT or W) and indirect (SDSS, protein content) measurements of quality (Dong et al., 1992) in parental and progenies will have critical importance. Since higher yields are the main objective of the breeding programme, strategies for mediumhigh grain yielding with acceptable quality is necessary and evaluation of quality at all stages of agronomic evaluation should be designed. It was shown that most of the varieties had the required $G l u-1$ alleles and high values of studied physical measures of quality as opposed to what was originally thought. Therefore, this study has confirmed that concerns of poor baking quality is unlikely to be due to Glu-1 allelic variations alone.

\section{ACKNOWLEDGEMENT}

We acknowledge the support of Adet Agricultural Research Centre in Ethiopia and Department of Plant Sciences at Free State University in South Africa.

\section{REFERENCES}

Alamerew, S., Chebotar, S., Huang, X., Ro“der, M. and Bo"rner, A. 2004. Genetic diversity in Ethiopian hexaploid and tetraploid wheat 
germplasm assessed by microsatellite markers. Genetic Resources and Crop Evolution 51:559-567.

Bedõ, Z., Kárpáti, M., Vida, G. Kramarikkissimon, J. and Láng. 1995. Good bread making quality wheat (Triticum aestivum, L.) genotypes with $2+12$ subunit composition at the Glu-D1 locus. Cereal Research Communication 23(3):283-289.

Bingham, J. and Lupton, F.G.H. 1987. Production of new varieties at integrated research approach to plant breeding. In: Yield of cereals. Royal Agricultural Society of England, National Agricultural Centre, Stoneleigh, UK.

Cornish, G. B., Panozzo, J. F. and Wrigley, C. W. 1999. Victorian wheat protein families. In: OBrien, L., Blakeney, A. B. Ross, A. S. and Wrigley, C.W. (Eds.), pp. 183-188. Cereals 98. Proceedings of the $48^{\text {th }}$ Australian Cereal Chemistry Conference. RACI: Melbourne, Australia.

Dong, H., Sears, R.G., Cox, T.S., Hoseney, R.C., Lookhart, G.L. and Shorgen, M.D. 1992. relationship between protein composition and Mixograph and loaf characteristics in wheat. Cereal Chemistry 69(2):132-136.

Gupta, R. B., Singh, N. K. and Shepherd, K. W. 1989. The cumulative effect of allelic variation in LMW and HMW glutenin subunits on physical dough properties in progeny of two bread wheats. Theoretical and Applied Genetics 77:57-64.

Hailu, G. 1991. Bread wheat breeding and genetics in Ethiopia. In: Hailu, G., Tanner, D.G. and Mengistu, H. (Eds.), pp. 73-93. Wheat research in Ethiopia: A historical perspective. Addis Ababa. IAR/CIMMYT.

Igregas, G., Guedes-Pinto, H., Carnide, V. and Branlard, G. 1999. The high and low molecular weight glutenin subunit and ùgliadin composition of bread and durum wheats commonly grown in Portugal. Plant Breeding 118:297-302.

Jackson, E. A., Holt, L. M. and Payne, P. I. 1983. Characterisation of high-molecular-weight gliadin and low-molecular-weight glutenin subunits of wheat endosperm by twodimensional electrophoresis and chromosomal localisation of their controlling genes. Theoretical and Applied Genetics 66:29-37.

Kasarda, D. D. 1999. Glutenin polymers: The in vitro to in vivo transition. Cereal Foods World 44:566-571.

Kolster, P., van Eeuwijk, F.A. and van Gelder, W.M.J. 1991. Additive and epistatic effects of allelic variation at the high molecular weight glutenin subunit loci in determining the breadmaking quality of breeding lines of wheat. Euphytica 55:277-285.

Lukow, O.M. 1991. Screening of bread wheats for milling and baking quality- A Canadian perspective. Cereal Foods World 36(6):497501.

Lukow,O.M., Payne,P.I. and Tkachuk,R. 1989. The HMW glutenin subunit composition of Canadian wheat cultivars and their associations with break making quality. Journal of the Science of Food and Agriculture 46:451.

MacRitchie, F., du Cros, D. L. and Wrigley, C. W. 1990. Flour polypeptides related to wheat quality. Advances in cereal science and technology 10:79-145

Morguno, A.I., Rogers, W.J., Sayers, E.J. and Metakovsky, E.V. 1990. The high molecular weight glutenin subunits of Soviet grown varieties. Euphytica 51:41-52.

Nakamura, H. 2001. Genetic diversity of highmolecular-weight glutenin subunits compositions of in landraces of hexaploid wheat from Japan. Euphytica 120:227-234.

Ng, P.K.W. and Bushuk, W. 1988. Statistical relationship between high molecular weight subunits of glutenin and bread making quality of Canadian grown wheats. Cereal Chemistry 65(5): 408-413.

Payne, P.I. and Lawrence, G.J. 1983. Catalogue of alleles for the complex gene loci, Glu-A1, GluB1 and Glu-D1 which code for high molecular weight sub units of glutenins in hexaploid wheat. Cereal Research Communication 11:29-35.

Payne, P. I., Law, C. N. and Mudd, E. E. 1980. Control by homoeologous group 1 chromosomes of the high-molecular-weight subunits of glutenin, a major protein of wheat endosperm. Theoretical and Applied Genetics 58:113-120. 
Payne, P.I. 1987. Genetic of wheat storage proteins and the effect of allelic variation on bread making quality. Annual Reviews in Plant Physiology 8:141-153.

Payne, P.I., Mark A., N., Krattiger A.F. and Holt L.M. 1987. The relationship between HMW glutenin subunits composition and the bread making quality of British-grown wheats. Journal of the Science of Food and Agriculture 40:51-65.

Payne, T.S, Wanjama, J.K. and Girma, B. 2001. Eastern African wheat pool. In: Bonjean, A.P. and Angus, W.J. (Eds.). The wheat world book: A history of wheat breeding. Lavoisier publishing, France.

Pogna, N.E. and Mellini, F. 1986. Alla ricerca delle basi biochemiche e genetiche della qualita del glutine.L'Inform Agr 42:65-66.

Singh N.K., Shepherd and Cornish, G.B. 1991. A simplified SDS-PAGE procedure for separating LMW subunits of glutenins. Journal of Cereal Science 14:203-208.
Tanner, D.G. and Mwangi, W. 1991. Current issues in wheat research and production in Eastern, Central and Southern Africa. In: Tanner, D.G. and Mwangi (Eds.), pp.17-36. Constraints and achievements. Seventh regional wheat workshop for Eastern, Central and Southern Africa, Nakuru, Kenya: CIMMYT.

Vavilov, N.I. 1931. The wheat of Abyssinia and their place in the general system of wheats. Bulletin of Applied Botany, Genetics, and Plant Breeding, Supplement 51. 233 pp.

Weegels, P. L, Hamer, R. J. and Schofield, J. D. 1996. Functional properties of wheat glutenin. Journal of Cereal Science 23:1-18.

Worland, T. and Snape, J.W. 2001. Genetic basis of worldwide wheat varietal improvement. In: Bonjean, A.P. and Angus, W.J. (Eds.), pp. 8485. The world wheat book: A history of wheat breeding. Lavoisier Publishing Inc., France.

Wrigley, C. 2002. The next breakthrough in cereal chemistry-rapid quality testing. Cereals Food World47(3):117-118. 